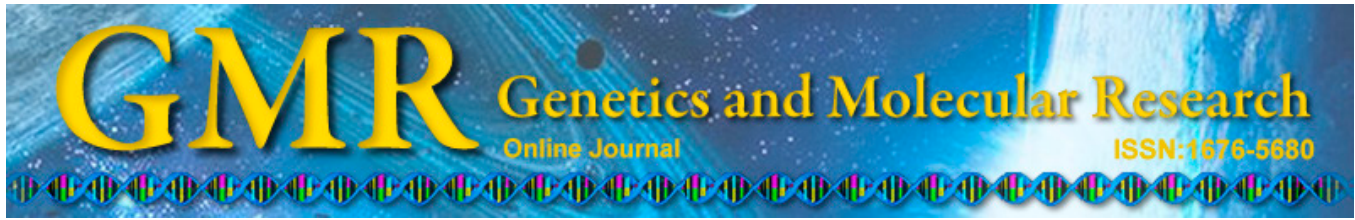

\title{
Effects of washed platelets vs platelet-rich plasma on the proliferation and mineralization of rat dental pulp cells
}

\author{
L. Zhang' ${ }^{1}$ Y.H. Xie ${ }^{2}$ and B.R. Lin ${ }^{1}$
}

${ }^{1}$ The First Affiliated Hospital of Liaoning Medical University, Jinzhou, China ${ }^{2}$ Department of Stomatology, Xi'an No. 4 Hospital, Xi'an, China

Corresponding authors: B.R. Lin / Y.H. Xie

E-mail: linbenruilmu@126.com / xieyanhuads@126.com

Genet. Mol. Res. 14 (3): 9486-9496 (2015)

Received November 13, 2014

Accepted April 28, 2015

Published August 14, 2015

DOI http://dx.doi.org/10.4238/2015.August.14.12

\begin{abstract}
We examined the effects of washed platelets (WPLTs) and platelet-rich plasma (PRP) on the proliferation and mineralization of rat dental pulp cells. Rat dental pulp cells were separated, cultured, and identified. Medium containing 1, 10,100, or $500 \mathrm{~mL} / \mathrm{L}$ PRP or WPLTs was added to 4th generation cells. The MTS method was used to determine cell proliferation. Alizarin red staining was used to observe the formation of mineralized nodules after cell mineralization and induction for 10 and 20 days under different culture conditions, and the areas of the mineralized nodules formed 20 days after induction were computed. The addition of 1,10 , and $100 \mathrm{~mL} / \mathrm{L}$ WPLTs or PRP significantly promoted rat dental pulp cell proliferation $(\mathrm{P}<0.05)$ whereas $500 \mathrm{~mL} / \mathrm{L}$ WPLTs or PRP had no significant effect $(\mathrm{P}>0.05)$. Under the same concentrations, no significant differences on cell proliferation were observed between WPLT and PRP treatments ( $>0.05$ in all groups). After 10 days mineralization and culture, the 100 and $500 \mathrm{~mL} / \mathrm{L}$ WPLT and PRP group positive nodule rates were significantly higher than those of the low concentration and the control groups $(\mathrm{P}<0.05)$. After 20 days, the areas of the mineralized nodules formed in the 100 and $500 \mathrm{~mL} / \mathrm{L}$ WPLT and
\end{abstract}


PRP groups were significantly larger than those in the control group $(\mathrm{P}<$ 0.05). These results demonstrate that both WPLTs and PRP are equally able to significantly promote the proliferation and calcification of rat dental pulp cells under a certain range of concentrations.

Key words: Washed platelets; Platelet-rich plasma; Dental pulp cells; Proliferation; Mineralization

\section{INTRODUCTION}

The biological principle for the treatment of dental pulp diseases is to retain the activity of residual healthy dental pulp to the greatest extent in order to maintain the nutrition of the hard tissues, particularly of the dental crown, thus reducing the risk of developing enhanced brittleness of hard dental tissues due to inactivation of the dental pulp and improving the tooth life (Johns and Vidyanath, 2011). Currently, there is no effective therapeutic method to retain the activity of healthy dental pulp or to promote the regeneration of residual dental pulp tissue.

Autologous platelet-rich plasma (PRP) contains various essential growth factors for tissue growth and repair (Zhao et al., 2013). It has been reported that PRP plays a role in promoting the healing of wounds of hard and soft tissues and in the regeneration of osseous tissues. Researchers have applied PRP to such clinical treatment fields as orthopedics, oral cavity dental implants, and periodontal surgery (Zhu et al., 2012, 2013). Studies have found that that the washed platelets (WPLTs) obtained from PRP following removal of the plasma play a significant role in promoting the proliferation of rat dental pulp cells, suggestion the potential for application of improved PRP towards retention treatment of vital dental pulp and even towards regeneration treatment of dental pulp tissues (Orhan et al., 2012; Wang et al., 2013). Currently, there is no uniform standard for the method of PRP preparation, mode of activation of blood platelets, concentration of blood platelets in PRP, and so on. In addition, there is no clear understanding of the complex biological mechanisms of the mutual synergistic effects of the various growth factors in PRP. Therefore, no general acceptance has been reached on the efficacy of PRP in clinical applications. It is therefore necessary to conduct a more basic and systematic study on the preparation, activation, and clinical application methods of PRP.

This study aimed to determine the ideal concentration of PRP and WPLTs for promoting the proliferation and mineralization of rat dental pulp cells, and to provide experimental data necessary for developing research on the in vivo application of PRP toward the retention of vital dental pulp and regeneration of crushed tissues.

\section{MATERIAL AND METHODS}

\section{Materials}

Healthy specific pathogen free Sprague Dawley rats aged 50-60 days and weighing 180-200 g were purchased from the Shanghai Laboratory Animal Centre of The Chinese Academy of Sciences (Shanghai, China).

Fetal bovine serum (FBS) was purchased from Beijing Ruixiang Biotechnology Co., Ltd. (Beijing, China); $\beta$-sodium glycerophosphate was purchased from Beijing Bole Bioscience Development Co. Ltd. (Beijing, China); L-ascorbic acid was purchased from Shanghai 
Baoman Biotechnology Co. Ltd. (Shanghai, China); alkaline phosphatase quantitation kits were purchased from Shanghai Weijing Biotechnology Co., Ltd. (Shanghai, China); and Coomassie blue staining protein quantification kits were purchased from Santa Cruz Biotechnology (Santa Cruz, CA, USA).

The Mac-Lab complete blood cell analyzer was purchased from GE Healthcare (Piscataway, NJ, USA); TS cell proliferation determination kits were purchased from Thermo Fisher Scientific (Waltham, MA, USA); the LT2014 microplate reader was purchased from LEAD-TECH Scientific Instrument Co., Ltd. (Shanghai, China); the X22 inverted phase contrast microscope was purchased from Olympus (Tokyo, Japan); and the centrifuge was purchased from Beijing Jingli Centrifuge Co., Ltd. (Beijing, China).

\section{Isolation and culture of primary rat dental pulp cells}

The SD rats were sacrificed by cervical vertebra dislocation. The whole mandible was disassociated after the skin was sterilized with $75 \%$ ethyl alcohol for 30 min and placed into phosphate buffered saline (PBS) containing double-antibody (Penicillin-streptomycin). The hard tissues were crushed with vascular forceps in a super-clean bench. The dental pulp of a lower incisor was taken with a barbed broach and 1/3 of the root tip was cut off. The dental pulp tissue was sheared into tissue blocks with an approximate size of $0.5 \mathrm{~mm}^{3}$ in a glass culture dish containing culture medium, digested with $3 \mathrm{mg} / \mathrm{mL}$ Type I collagenase solution at $37^{\circ} \mathrm{C}$ for $1 \mathrm{~h}$ in a water bath, pipetted gently for $10 \mathrm{~min}$, and centrifuged at $31,000 \mathrm{r} / \mathrm{min}$ for $10 \mathrm{~min}$ after the tissue blocks became dissociated. The pellet was sufficiently pipetted to form a suspension after the supernatant was discarded and culture medium containing 10\% FBS was added, then was transferred into a 6-well microplate and placed in an incubator containing 5\% (volume fraction) $\mathrm{CO}_{2}$ for culture at $37^{\circ} \mathrm{C}$. An inverted microscope was used to observe cell adhesion and growth. Half of the solution volume was replaced on alternate days (Muramatsu et al., 2013).

\section{Isolation, culture, and proliferation of rat dental pulp cells}

The culture supernatant of the primary cells was collected, centrifuged at $3000 \mathrm{r} / \mathrm{min}$ for $10 \mathrm{~min}$, filtered with a $0.22-\mu \mathrm{m}$ disposable filter, and combined with isovolumetric lowsugar DMEM culture medium containing 10\% FBS. This mixture served as the adaptive culture medium for the culture of dental pulp cells. The cell colonies were selected and transferred to a 96-well microplate for continuous culture and amplification after the primary cells had been cultured for $48 \mathrm{~h}$. The cells were expanded gradually to culture flasks using passage at a 1:2-1:4 ratio following trypsinization once the cells had reached $80-90 \%$ confluence (Qu and Liu, 2013).

\section{Identification of the rat dental pulp cell phenotype}

Actively growing 3rd-generation dental pulp cells were harvested by trypsinization, re-suspended with culture medium, and inoculated into a 6-well microplate containing sterilized slides after the cell concentration had been adjusted to $1 \times 10^{5} / \mathrm{mL}$. The microplates were cultured for $24 \mathrm{~h}$, washed three times with PBS after the cells had adhered to the slides, fixed with $4 \%$ paraformaldehyde for $30 \mathrm{~min}$ at room temperature, and washed an additional 3 times with PBS. The subsequent steps were completed in accordance with the requirements of the immunohistochemical staining kit (Beckman Coulter, CA, USA). 


\section{PRP and WPLT preparation methods}

Venous blood $(30 \mathrm{~mL})$ was drawn from a rat, transferred to $10 \mathrm{~mL}$ centrifuge tubes, and centrifuged for $10 \mathrm{~min}$ at $1000 \mathrm{~g}$, and $10^{\circ} \mathrm{C}$. Then the supernatant plasma, albumin, and a few erythrocytes in the vicinity of the interface were pipetted, transferred to another centrifuge tube, and centrifuged again for $10 \mathrm{~min}$ at $3000 \mathrm{r} / \mathrm{min}$ and $10^{\circ} \mathrm{C}$. The supernatant plasma was pipetted. The plasma $(3 \mathrm{~mL})$ and sediment at the bottom of the centrifuge tube were retained and pipetted repeatedly to finish the preparation of PRP after blood platelets had been again re-suspended. Blood platelet counting was performed for platelet poor plasma (PPP) and PRP with a complete blood cell analyzer. PRP ( $3 \mathrm{~mL})$ was taken, centrifuged for $10 \mathrm{~min}$ at 3000 $\mathrm{r} / \mathrm{min}$ and $10^{\circ} \mathrm{C}$ after addition of $300 \mu \mathrm{L} 50 \mathrm{mM}$ EDTA/a-MEM, washed with $3 \mathrm{~mL} 50 \mathrm{mM}$ EDTA/a-MEM after the supernatant was discarded, and centrifuged under the same conditions. The supernatant was discarded again. The concentration of precipitated blood platelets was adjusted to the same as that of the PRP with a-MEM to complete the preparation of WPLTs (Chang et al., 2013).

\section{Quantitative determination of dental pulp cell proliferation}

Proliferating 4th generation rat dental pulp cells were taken, digested, counted, diluted to $1 \times 10^{5} / \mathrm{mL}$ cell suspension, and inoculated into a 96-well microplate at $100 \mu \mathrm{L} / \mathrm{well}$. Cells were cultured in a cell incubator for $24 \mathrm{~h}$ and washed 3 times with PBS after the culture medium was discarded. DMEM culture media containing 1, 10, 100, and $500 \mathrm{~mL} / \mathrm{L}$ PRP and WPLTs were added, respectively. DMEM not containing the above specimens was cultured continuously in the incubator for 3 days as a blank control. For detection of proliferation, the culture medium on each well was discarded, and each well was washed 3 times with PBS, followed by addition of DMEM culture medium $(100 \mu \mathrm{L})$ and MTS reagent $(100 \mu \mathrm{L})$ to each well. Each well was incubated in the dark for $2 \mathrm{~h}$ at $37^{\circ} \mathrm{C}$. The OD value was determined with a microplate reader at $490 \mathrm{~nm}$.

\section{Mineralization and culture of dental pulp cells}

A suspension of rat dental pulp cells $(1 \times 105 / \mathrm{mL})$ was inoculated into a 24-well microplate at $500 \mu \mathrm{L} /$ well and the culture medium was supplemented to $1 \mathrm{~mL}$. After the cells were cultured in an incubator for $24 \mathrm{~h}$, the culture medium was replaced respectively by $1 \mathrm{~mL}$ mineralization culture media containing 1, 10, 100, or $500 \mathrm{~mL} / \mathrm{L}$ PRP or WPLTs. Two parallel groups were established for each culture medium at different concentrations with 20 wells for each group. One group was fixed with neutral formalin for $30 \mathrm{~min}$ after being continuously cultured for 10 days, and the cells stained with Alizarin red solution $(0.1 \%)$ for $10 \mathrm{~min}$. The formation of mineralization nodules was observed microscopically (mineralization nodules were brownish red). The positive rate of mineralization nodules was also calculated (the rate of wells with mineralization nodules formed among the total number of wells observed in the same group). Another group was subjected to Alizarin red staining after being continuously cultured for 20 days. We randomly selected ten mineralization nodules from each group and photographed them under an inverted microscope. The area of mineralization nodules was measured with the grid method using the Bio-Rad image analysis software. 


\section{Statistical analysis}

Statistical analysis was performed using the SPSS 13.0 software (SPSS, Chicago, IL, USA). The experimental results data are reported as means \pm standard deviation. The comparison among groups was performed using the least significant difference (LSD) method. $\mathrm{P}<$ 0.05 indicated statistical significance.

\section{RESULTS}

\section{Morphological observation}

The dissociated tissue blocks and unicellular suspensions obtained after enzymatic digestion were inoculated into a 6-well microplate. Most tissue blocks were able to adhere to the well bottom. Adhesion of monoplasts was observed microscopically at $24 \mathrm{~h}$. Cells extended and grew and most of them became fibroblasts; a small number of cells proliferated rapidly and small cell colonies formed at $72 \mathrm{~h}$ (Figure 1A). Many monoplasts dissociated from the vicinity of the tissue blocks at around 7 days (Figure 1B). It was observed that the number of cells increased, a fraction of the cells grew in colonies, and the cells were arranged densely at around 14 days after culture. Almost all of the dental pulp cells obtained from cloning, culturing, and amplification of cells were long-shuttle shaped; some cells exhibited projections (Figure $1 \mathrm{C}$ and D), the cellular status was good, and the average passage time was 5-6 days.
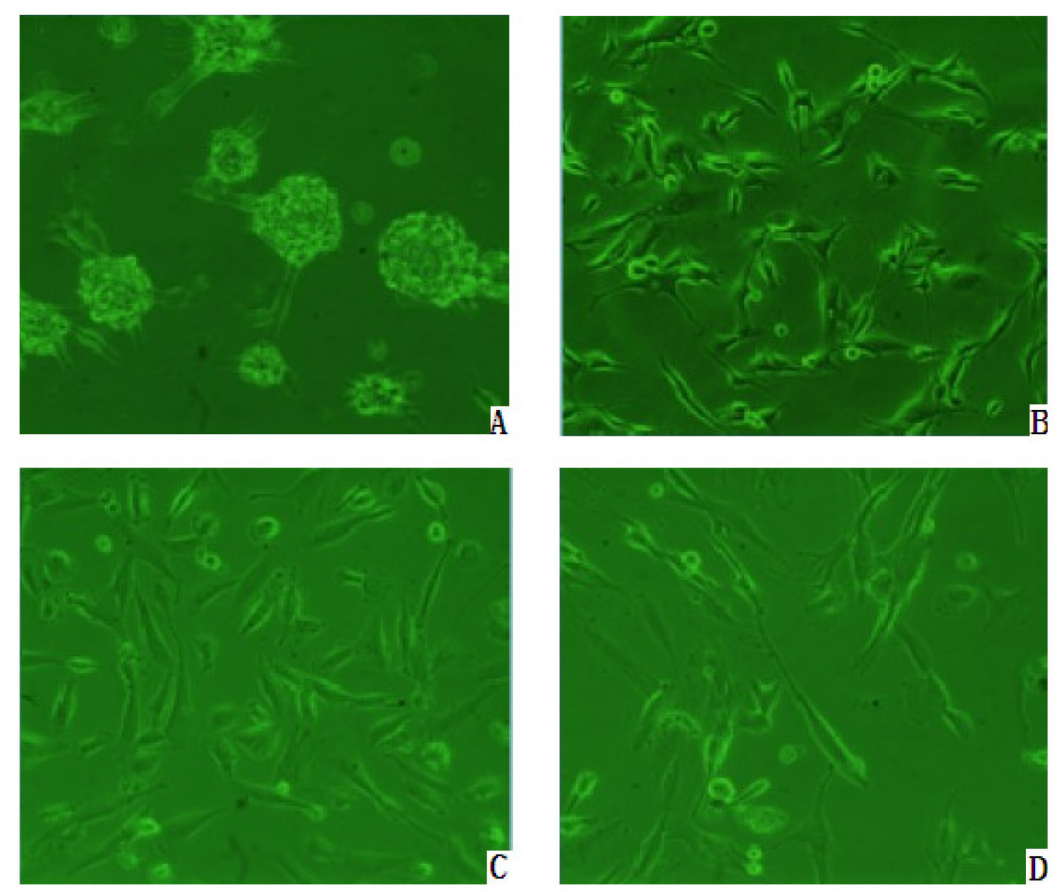

Figure 1. Cellular morphological changes at different times. Cells are shown at (A) 72 h; (B) 7 days; and (C) 14 days after plating. 


\section{Identification of the rat dental pulp stem cell phenotype}

Immunohistochemical staining results demonstrated that rat dental pulp cells exhibited positive CD44 and CD29 expression whereas expression of CD34 was scored as negative (Figure 2A-C).
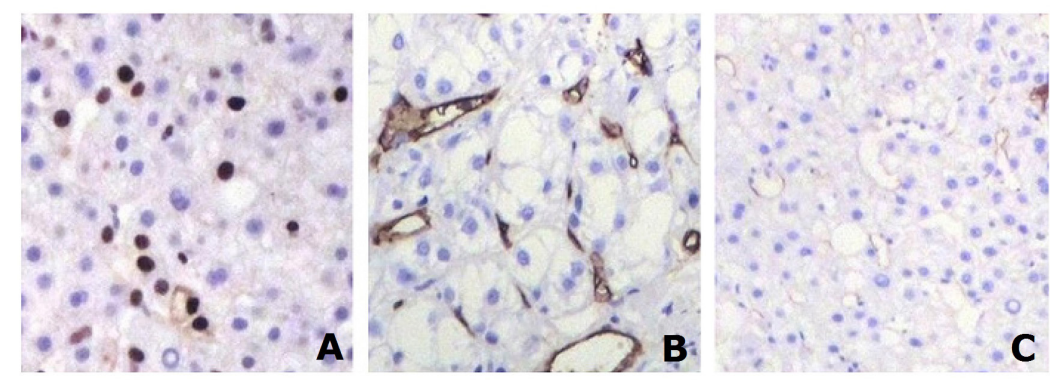

Figure 2. Identification of rat dental pulp stem cell surface markers (200X). (A) CD44 negative expression; (B) CD29 positive expression; (C) CD34 negative expression.

\section{Blood platelet counts in whole blood, PPP, and PRP}

The average counts of blood platelets in whole blood, PPP, and PRP were 137.2 \pm 26.5 $\left(10^{9} / \mathrm{mL}\right), 392.4 \pm 47.2\left(10^{9} / \mathrm{mL}\right)$, and $12.4 \pm 1.7\left(10^{9} / \mathrm{mL}\right)$, respectively. The average concentration of blood platelets in PRP was $4.63 \pm 0.38$ times that in whole blood.

\section{Effects of WPLTs and PRP at different concentrations on the proliferation of rat dental pulp cells}

WPLTs and PRP $(1,10$, and $100 \mathrm{~mL} / \mathrm{L})$ significantly promoted the proliferation of rat dental pulp cells compared with the control group ( $\mathrm{P}<0.05$ in all groups). However, the effect was not strengthened with increase in concentration; WPLTs and PRP at $500 \mathrm{~mL} / \mathrm{L}$ did not stimulate the proliferation of rat dental pulp cells (compared with the control group, $\mathrm{P}>$ 0.05 was observed in all groups). There was no significant difference between WPLT and PRP treatments in promoting the proliferation of rat dental pulp cells $(\mathrm{P}>0.05$ was observed in all groups) (Table 1 and Figure 3).

Table 1. Effects of WPLTs and PRP at different concentrations on the proliferation of rat dental pulp cells.
\begin{tabular}{llc}
\hline & \\
\hline Group & & OD value \\
\hline DMEM (control) & $1 \mathrm{~mL} / \mathrm{L}$ & $0.4745 \pm 0.0013$ \\
WPLT & $10 \mathrm{~mL} / \mathrm{L}$ & $0.9762 \pm 0.0054^{*}$ \\
& $100 \mathrm{~mL} / \mathrm{L}$ & $0.9525 \pm 0.0041^{*}$ \\
& $500 \mathrm{~mL} / \mathrm{L}$ & $0.9211 \pm 0.0033^{*}$ \\
PRP & $1 \mathrm{~mL} / \mathrm{L}$ & $0.6812 \pm 0.0026$ \\
& $10 \mathrm{~mL} / \mathrm{L}$ & $0.8724 \pm 0.0051^{*}$ \\
& $100 \mathrm{~mL} / \mathrm{L}$ & $0.8692 \pm 0.0044^{*}$ \\
& $500 \mathrm{~mL} / \mathrm{L}$ & $0.8144 \pm 0.0035^{*}$ \\
\hline
\end{tabular}

*Compared with the control group, $\mathrm{P}<0.05$. DMEM = Dulbecco's modified Eagle medium; WPLTs = washed platelets; $\mathrm{PRP}=$ platelet rich plasma. 


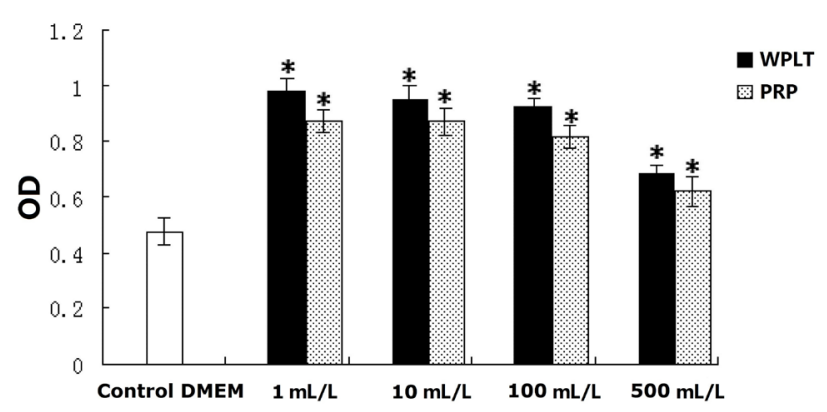

Figure 3. Effects of WPLTs and PRP at different concentrations on the proliferation of rat dental pulp cells. $*$ Compared with the control group, $\mathrm{P}<0.05$. WPLTs $=$ washed platelets; $\mathrm{PRP}=$ platelet rich plasma.

\section{Mineralization and culture of dental pulp cells}

The positive rates of mineralization nodules in the 100 and $500 \mathrm{~mL} / \mathrm{L}$ WPLT and PRP groups at 10 days after continuous mineralization and culture were significantly higher than those in the low concentration and the control groups $(\mathrm{P}<0.05)$. The positive rates of the $100 \mathrm{~mL} / \mathrm{L}$ WPLT and PRP groups were the highest. After twenty days of mineralization and culture, mineralization nodules had formed in the culture wells of all of the experimental and the control groups but the areas of the mineralization nodules formed in the 100 and $500 \mathrm{~mL} / \mathrm{L}$ WPLT and PRP groups were significantly larger than those in the control group $(\mathrm{P}<0.05)$. The areas of the mineralization nodules formed in the $100 \mathrm{~mL} / \mathrm{L}$ WPLT and PRP groups were the largest (Tables 2 and 3, and Figure 4).

Table 2. Mineralization nodule formation in dental pulp cells 10 days after continuous mineralization and culture.

\begin{tabular}{|c|c|c|c|c|}
\hline Group & & Positive & Negative & Positive rate (\%) \\
\hline DMEM (control) & & 0 & 20 & 0 \\
\hline \multirow[t]{4}{*}{ WPLTs } & $1 \mathrm{~mL} / \mathrm{L}$ & 1 & 19 & 5 \\
\hline & $10 \mathrm{~mL} / \mathrm{L}$ & 3 & 17 & 15 \\
\hline & $100 \mathrm{~mL} / \mathrm{L}$ & 16 & 4 & $80 *$ \\
\hline & $500 \mathrm{~mL} / \mathrm{L}$ & 11 & 9 & $55^{*}$ \\
\hline \multirow[t]{4}{*}{ PRP } & $1 \mathrm{~mL} / \mathrm{L}$ & 2 & 18 & 10 \\
\hline & 10 mL/L & 5 & 15 & 25 \\
\hline & $100 \mathrm{~mL} / \mathrm{L}$ & 14 & 6 & $70^{*}$ \\
\hline & $500 \mathrm{~mL} / \mathrm{L}$ & 12 & 8 & $60 *$ \\
\hline
\end{tabular}

*Compared with the control group, $\mathrm{P}<0.05$. DMEM $=$ Dulbecco's modified Eagle medium; WPLT $=$ washed platelets; PRP = platelet rich plasma.

Table 3. Areas of the mineralization nodules formed in dental pulp cells induced by WPLTs and PRP at different concentrations.

\begin{tabular}{lcc}
\hline Group & & Mineralization nodule area $\left(\mathrm{mm}^{2}\right)$ \\
\hline DMEM (control) & $1 \mathrm{~mL} / \mathrm{L}$ & $0.0371 \pm 0.0012$ \\
WPLTs & $10 \mathrm{~mL} / \mathrm{L}$ & $0.0724 \pm 0.0026$ \\
& $100 \mathrm{~mL} / \mathrm{L}$ & $0.0925 \pm 0.0038$ \\
& $500 \mathrm{~mL} / \mathrm{L}$ & $0.1933 \pm 0.0127^{*}$ \\
PRP & $1 \mathrm{~mL} / \mathrm{L}$ & $0.1418 \pm 0.081^{*}$ \\
& $10 \mathrm{~mL} / \mathrm{L}$ & $0.0683 \pm 0.0024$ \\
& $100 \mathrm{~mL} / \mathrm{L}$ & $0.0825 \pm 0.025$ \\
& $500 \mathrm{~mL} / \mathrm{L}$ & $0.1735 \pm 0.107^{*}$ \\
\hline
\end{tabular}

*Compared with the control group, $\mathrm{P}<0.05$. DMEM $=$ Dulbecco's modified Eagle medium; WPLTs $=$ washed platelets; $\mathrm{PRP}=$ platelet rich plasma. 


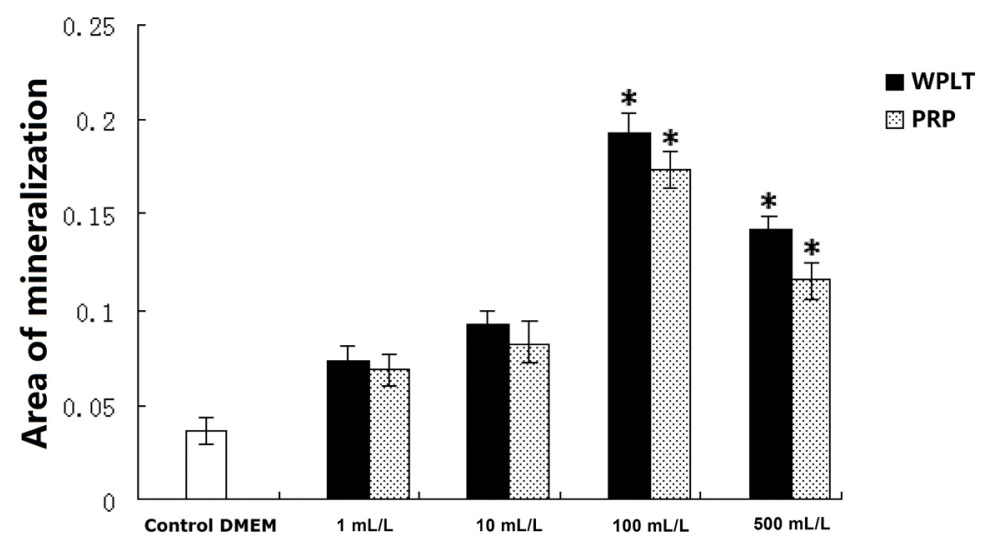

Figure 4. Comparison of the areas of the mineralization nodules formed in dental pulp cells induced by WPLTs and PRP at different concentrations. ${ }^{*}$ Compared with the control group, $\mathrm{P}<0.05$. WPLTs $=$ washed platelets; $\mathrm{PRP}=$ platelet rich plasma.

\section{DISCUSSION}

Currently, no ideal treatment method or material is available for the retention of vital dental pulp or for regeneration treatment of dental pulp tissues. The calcium hydroxide method commonly used clinically in the past has a certain curative effect in retention treatment of dental pulp but it is not an ideal biological material from histological aspects, as the dental pulp tissue in direct contact with this material will be subjected to necrosis, potentially leading to outcomes such as calcification or degeneration of the residual dental pulp (Morad et al., 2013; Vishwanath et al., 2013). In addition, the heterogeneous or allogeneic biological materials currently being studied and used in retention treatment of vital dental pulp, such as sintered bovine-derived powder and dentin powder, impart a risk of infectious diseases such as HIV or variant Creutzfeldt-Jakob (mad cow) disease (Alkaisi et al., 2013; Saito et al., 2013). Furthermore, the general method for the treatment of dental pulp diseases is root canal therapy, which primarily removes the whole dental pulp. The clinical effect of this treatment is definitive but it does not comply with the biological treatment principle of retaining healthy dental pulp and dental tissues to the greatest extent. The teeth that consequently lose the dental pulp nutrition will later exhibit complications including dental crown discoloration, increased dental brittleness, susceptibility to fracture, and secondary periapical disease (Murakami et al., 2013; Young et al., 2013). Therefore, it is of significance to discuss and identify a new safe and effective treatment method or material for vital dental pulp therapeutics, and particularly for regeneration treatment of dental pulp tissue.

Autologous PRP contains various growth factors necessary for tissue growth and trauma repair in the organism. In recent years, PRP has been widely used in such clinical treatment fields as orthopedics, oral cavity dental implantation, and regeneration of the periodontium (Kim et al., 2010; Torabinejad and Faras, 2012). At present, most reports of animal experimental and clinical research have found that PRP is able to significantly promote the healing of hard and soft tissues and the regeneration of osseous tissues (Khorsand et al., 2013). However, there has been no study on the use of PRP in promoting the healing of dental pulp trauma and 
the regeneration of dental pulp tissues. Furthermore, many basic problems in clinical applications of PRP remain to be solved, such as PRP preparation and activation methods, the identification of effective constituents, ideal platelet concentrations, or the action mechanisms of various growth factors contained in blood platelets.

It has been reported that PRP has been widely used in various fields such as the promotion of osseous tissue regeneration, trauma repair, periodontium regeneration, and the promotion of dental implant healing (Rutkowski et al., 2010). The primary advantages of the clinical use of autologous PRP include the following: blood platelets contain a high amount of various growth factors that promote the repair and regeneration of organisms and tissues, and PRP is autologous and therefore exhibits reliable biological safety (Albanese et al., 2013; Hata et al., 2013). However, various growth factors present in blood platelets might only be released by activation using an appropriate approach. Currently, the most widely used activator is bovine thrombin ( $\mathrm{Li}$ et al., 2012).

The results from this study show that WPLTs and PRP are each able to significantly promote the proliferation of rat dental pulp cells at concentrations ranging from 1 to $100 \mathrm{~mL} / \mathrm{L}$, but that the promotional role was not strengthened with the increase of concentration beyond a certain threshold. On the contrary, when the concentrations of WPLTs and PRP reached 500 $\mathrm{mL} / \mathrm{L}$, their role in promoting cell proliferation was significantly reduced compared with that of the low concentration group. Previously, many researchers have also observed that the role of blood platelets in promoting cell proliferation reduced when the concentration of blood platelets was increased beyond a certain level (Varalakshmi et al., 2013).

An important indication of dental pulp repair is the formation of repaired dentin (Zhang et al., 2013). Dental pulp cells cultured in vitro are able to form mineralization nodules at the site where cellular nodules exhibit multilayer growth and can aggregate under the effect of mineralization induction solution (Laiteerapong et al., 2012). Some studies have discovered that these mineralized nodules are primarily comprised of a dentin-like mineralized matrix, which has the characteristics of dentin (Jiang et al., 2012; Jin et al., 2013). Thus, at present, the formation of mineralized nodules is regarded as an important biological indicator of the detection of dentin generated in dental pulp cells (Du et al., 2013). In this study, it was observed that, after 10 days of continuous mineralization and culture, the rates of formation of mineralization nodules in the 100 and $500 \mathrm{~mL} / \mathrm{L}$ WPLT and PRP groups were significantly higher than those in the low concentration and the control groups; however, after continuous mineralization and culture for 20 days, the largest mineralization nodules were formed in the $100 \mathrm{~mL} / \mathrm{L}$ WPLT and PRP groups. The results also show that WPLTs and PRP exhibit concentration specificity in promoting the differentiation and mineralization of dental pulp cells, i.e., excessively low or high concentrations will not exert the effect.

There was no significant difference identified between either WPLTs or PRP at the same concentrations in promoting the in vitro mineralization of dental pulp cells. This result is consistent with the role of WPLTs and PRP in promoting the proliferation of dental pulp cells, indicating that both PRP and WPLTs can be used for retention repair or for the regeneration treatment of dental pulp. However, the method for activation of blood platelets in WPLT used in our study is a simple physical approach (liquid nitrogen freeze-thawing) and therefore the overall biological safety of WPLTs is superior to that of PRP (Lazić et al., 2009). In addition, PRP exhibits a jelly-like consistency after being activated by bovine thrombin and it is difficult therefore to mix it sufficiently with the biological pulp capping material. The WPLT preparation can be readily mixed with biological pulp capping material due to its fluidity after being 
activated by freeze-thawing (Nikolidakis and Jansen, 2008). Hence, we suggest that WPLTs are more suitable for in vivo experiments and the retention treatment of dental pulp in clinical applications than is PRP.

\title{
Conflicts of interest
}

\author{
The authors declare no conflict of interest.
}

\section{REFERENCES}

Albanese A, Licata ME, Polizzi B and Campisi G (2013). Platelet-rich plasma (PRP) in dental and oral surgery: from the wound healing to bone regeneration. Immun. Ageing 10: 23.

Alkaisi A, Ismail AR, Mutum SS, Ahmad ZA, et al. (2013). Transplantation of human dental pulp stem cells: enhance bone consolidation in mandibular distraction osteogenesis. J. Oral Maxillofac. Surg. 71: 1758.e1-13.

Chang MC, Lin LD, Tseng HC, Chang BE, et al. (2013). Growth and differentiation factor-5 regulates the growth and differentiation of human dental pulp cells. J. Endod. 39: 1272-1277.

Du R, Wu T, Liu W, Li L, et al. (2013). Role of the extracellular signal-regulated kinase 1/2 pathway in driving tricalcium silicate-induced proliferation and biomineralization of human dental pulp cells in vitro. J. Endod. 39: 1023-1029.

Hata M, Naruse K, Ozawa S, Kobayashi Y, et al. (2013). Mechanical stretch increases the proliferation while inhibiting the osteogenic differentiation in dental pulp stem cells. Tissue Eng. Part A 19: 625-633.

Jiang L, Peng WW, Li LF, Yang Y, et al. (2012). Proliferation and multilineage potential of CXCR4-positive human dental pulp cells in vitro. J. Endod. 38: 642-647.

Jin H, Park JY, Choi H and Choung PH (2013). HDAC inhibitor trichostatin A promotes proliferation and odontoblast differentiation of human dental pulp stem cells. Tissue Eng. Part A 19: 613-624.

Johns DA and Vidyanath S (2011). Revitalization of tooth with necrotic pulp and open apex by using platelet-rich plasma: a case report. J. Endod. 37: 743.

Khorsand A, Eslaminejad MB, Arabsolghar M, Paknejad M, et al. (2013). Autologous dental pulp stem cells in regeneration of defect created in canine periodontal tissue. J. Oral Implantol. 39: 433-443.

Kim BK, Kim SG, Kim SY, Lim SC, et al. (2010). A comparison of bone generation capability in rabbits using tooth ash and plaster of Paris with platelet-rich plasma or fibrin sealant. Oral Surg. Oral Med. Oral Pathol. Oral Radiol. Endod. 110: e8-14.

Laiteerapong A, Lochaiwatana Y, Hirata I, Okazaki M, et al. (2012). A novel glass ionomer cement containing $\mathrm{MgCO}(3)$ apatite induced the increased proliferation and differentiation of human pulp cells in vitro. Dent. Mater. J. 31: 772-778.

Lazić Z, Bubalo M, Petković-Curcin A, Dukat M, et al. (2009). Therapeutic use of platelet-rich plasma in oral surgery. Vojnosanit Pregl. 66: 821-825.

Li X, Yang G and Fan M (2012). Effects of homeobox gene distal-less 3 on proliferation and odontoblastic differentiation of human dental pulp cells. J. Endod. 38: 1504-1510.

Morad G, Kheiri L and Khojasteh A (2013). Dental pulp stem cells for in vivo bone regeneration: A systematic review of literature. Arch. Oral Biol. 58: 1818-1827.

Murakami M, Horibe H, Iohara K, Hayashi Y, et al. (2013). The use of granulocyte-colony stimulating factor induced mobilization for isolation of dental pulp stem cells with high regenerative potential. Biomaterials 34: 9036-9047.

Muramatsu T, Yuasa K, Ebihara K, Shibukawa Y, et al. (2013). Glucose-free conditions induce the expression of AMPK in dental pulp cells. Arch. Oral Biol. 58: 1603-1608.

Nikolidakis D and Jansen JA (2008). The biology of platelet-rich plasma and its application in oral surgery: literature review. Tissue Eng. Part B Rev. 14: 249-258.

Orhan EO, Maden M and Senguüven B (2012). Odontoblast-like cell numbers and reparative dentine thickness after direct pulp capping with platelet-rich plasma and enamel matrix derivative: a histomorphometric evaluation. Int. Endod. J. 45: 317-325.

Qu T and Liu X (2013). Nano-structured gelatin/bioactive glass hybrid scaffolds for the enhancement of odontogenic differentiation of human dental pulp stem cells. J. Mater. Chem. B Mater. Biol. Med. 1: 4764-4772.

Rutkowski JL, Johnson DA, Radio NM and Fennell JW (2010). Platelet rich plasma to facilitate wound healing following tooth extraction. J. Oral Implantol. 36: 11-23.

Saito K, Nakatomi M and Ohshima H (2013). Dynamics of bromodeoxyuridine label-retaining dental pulp cells during pulpal healing after cavity preparation in mice. J. Endod. 39: 1250-1255.

Genetics and Molecular Research 14 (3): 9486-9496 (2015)

CFUNPEC-RP www.funpecrp.com.br 
Torabinejad M and Faras H (2012). Clinical and histological report of a tooth with an open apex treated with regenerative endodontics using platelet-rich plasma. J. Endod. 38: 864-868.

Varalakshmi PR, Kavitha M, Govindan R and Narasimhan S (2013). Effect of statins with alpha-tricalcium phosphate on proliferation, differentiation, and mineralization of human dental pulp cells. J. Endod. 39: 806-812.

Vishwanath VR, Nadig RR, Nadig R, Prasanna JS, et al. (2013). Differentiation of isolated and characterized human dental pulp stem cells and stem cells from human exfoliated deciduous teeth: An in vitro study. J. Conserv. Dent. 16: 423-428.

Wang Y, Yan M, Wang Z, Wu J, et al. (2013). Dental pulp stem cells from traumatically exposed pulps exhibited an enhanced osteogenic potential and weakened odontogenic capacity. Arch. Oral Biol. 58: 1709-1717.

Young F, Sloan A and Song B (2013). Dental pulp stem cells and their potential roles in central nervous system regeneration and repair. J. Neurosci. Res. 91: 1383-1393.

Zhang S, Yang X and Fan M (2013). BioAggregate and iRoot BP Plus optimize the proliferation and mineralization ability of human dental pulp cells. Int. Endod. J. 46: 923-929.

Zhao SN, Liu WF and Zhang ZT (2013). Effect of platelet-rich plasma on cell proliferation and osteogenic activity of pulp stem cells. Zhonghua Kou Qiang Yi Xue Za Zhi 48: 177-182.

Zhu X, Zhang C, Huang GT, Cheung GS, et al. (2012). Transplantation of dental pulp stem cells and platelet-rich plasma for pulp regeneration. J. Endod. 38: 1604-1609.

Zhu W, Zhu X., Huang GT, Cheung GS, et al. (2013). Regeneration of dental pulp tissue in immature teeth with apical periodontitis using platelet-rich plasma and dental pulp cells. Int. Endod. J. 46: 962-970. 